\title{
An Uneventful Pregnancy and Delivery in a Patient with Chronic Myeloid Leukemia
}

${ }^{1} \mathrm{~S}$ Prathima, ${ }^{2} \mathrm{CSBR}$ Prasad, ${ }^{3}$ Udaya Kumar, ${ }^{4} \mathrm{M}$ Narayanswamy

\begin{abstract}
The concomitant occurrence of chronic myeloid leukemia and pregnancy is estimated to be one in 75000-100000 pregnancies annually. We present a case of 28 years old lady with 36 weeks of gestation diagnosed as chronic myeloid leukemia in chronic phase. Her pregnancy and delivery was uneventful. She breast fed the baby for 3 weeks before initiating treatment. Close vigilance and relevant investigations are of paramount importance in recognizing this extremely rare disease during pregnancy.
\end{abstract}

Keywords: Pregnancy, Chronic myeloid leukemia, Delivery.

How to cite this article: Prathima S, Prasad CSBR, Kumar U, Narayanswamy M. An Uneventful Pregnancy and Delivery in a Patient with Chronic Myeloid Leukemia. J South Asian Feder Menopause Soc 2014;2(1):33-34.

Source of support: Nil

Conflict of interest: None

\section{INTRODUCTION}

Chronic myeloid leukemia (CML) is a myeloproliferative disorder that originates in an abnormal pluripotent bone marrow stem cell and is consistently associated with the Philadelphia $(\mathrm{Ph})$ chromosome and/or the BCR/ABL fusion gene. The disease is biphasic or triphasic characterized by an initial indolent chronic phase (CML-CP) followed by one or both of the aggressive transformed stages, accelerated phase (CML-AP) and the blast phase (CML-BP). ${ }^{1}$ The incidence of chronic myeloid leukemia in pregnancy is one is 75000-100000 pregnancies with a risk of leukostasis and placental insufficiency with consequent low birth weight, fetal prematurity and increased mortality. ${ }^{2}$ We report a case of a 28 years lady with 36 weeks of gestation in chronic phase of CML delivering a healthy male baby.

\section{CASE HISTORY}

A 28 years old woman, gravida 3, parity 2 and living 2 with 36 weeks of gestation presented with labor pains. Her

\footnotetext{
${ }^{1}$ Assistant Professor, ${ }^{2}$ Associate Professor, ${ }^{3,4}$ Professor

${ }^{1-3}$ Department of Pathology, Sri Devaraj URS Medical College Kolar, Karnataka, India

${ }^{4}$ Department of Obstetrics and Gynecology, Sri Devaraj URS Medical College, Kolar, Karnataka, India
}

Corresponding Author: S Prathima, Assistant Professor Department of Pathology, Sri Devaraj URS Medical College, Kolar Karnataka, India, e-mail: prathimapathology@rediffmail.com antenatal period was uneventful. Menstrual cycles were regular. Routine hemogram revealed a total leukocyte count of 1,03,000 cells/cumm, hemoglobin $11.7 \mathrm{~g} / \mathrm{dl}$, platelets $2,67,000$ cells/cumm, neutrophils $64 \%$, myelocytes $10 \%$, metamyelocytes $6 \%$, myeloblasts $2 \%$, lymphocytes $14 \%$, basophils $4 \%$ (Fig. 1). She was diagnosed as a case of CMLchronic phase in labor. She delivered a normal healthy male baby weighing $2.5 \mathrm{~kg}$ with Apgar score of 7 at 1 minute and 8 at 5 minutes with no abnormality and blood counts were normal. Repeat hemogram was done 24 hours after delivery which revealed, total leukocyte count 88,000 cells/ cumm, hemoglobin $10.8 \mathrm{~g} / \mathrm{dl}$ and platelets $3,60,000$ cells/ cumm (Fig. 2). Ultrasonography of abdomen after delivery showed splenomegaly. Bone marrow examination revealed hypercellular bone marrow with increased granulopoiesis and $2 \%$ blasts. Cytogenetic study (46,XY, t(9;22) (q34;q11), bcr/abl positive), confirmed the diagnosis of chronic phase CML. The child was breastfed for 3 weeks before starting therapy for chronic phase CML.

\section{DISCUSSION}

Leukemia during pregnancy is very rare. CML accounts for less than $10 \%$ of all leukemias during pregnancy. ${ }^{3} \mathrm{CML}$ is a clonal myeloproliferative disorder of a pluripotent stem cell, ${ }^{4}$ first described by John Hughes Bennett in 1845 at The Royal Infirmary of Edinburgh. ${ }^{5}$ Classically three phases of disease progression are recognized in CML: chronic phase (CP), accelerated phase (AP), and blast phase (BP). Frequently the diagnosis is made incidentally during a routine complete hemogram for unrelated reasons. Nearly $90 \%$ of patients with CML have their conditions diagnosed in the chronic phase as they have a competent immune system and may remain asymptomatic for prolonged period. Patients usually present with weakness, malaise and abdominal discomfort due to splenomegaly. ${ }^{6}$ The diagnosis is usually based on peripheral blood leukocytosis with basophilia, eosinophilia which is further confirmed on bone marrow examination and cytogenetic analysis.

Chronic myeloid leukemia was the first malignancy to have a specific chromosomal abnormality uniquely linked to it after the discovery of a minute chromosome now known as the Philadelphia $(\mathrm{Ph})$ chromosome, later defined to result from a $\mathrm{t}(9 ; 22)$ reciprocal chromosomal translocation. ${ }^{7}$ 


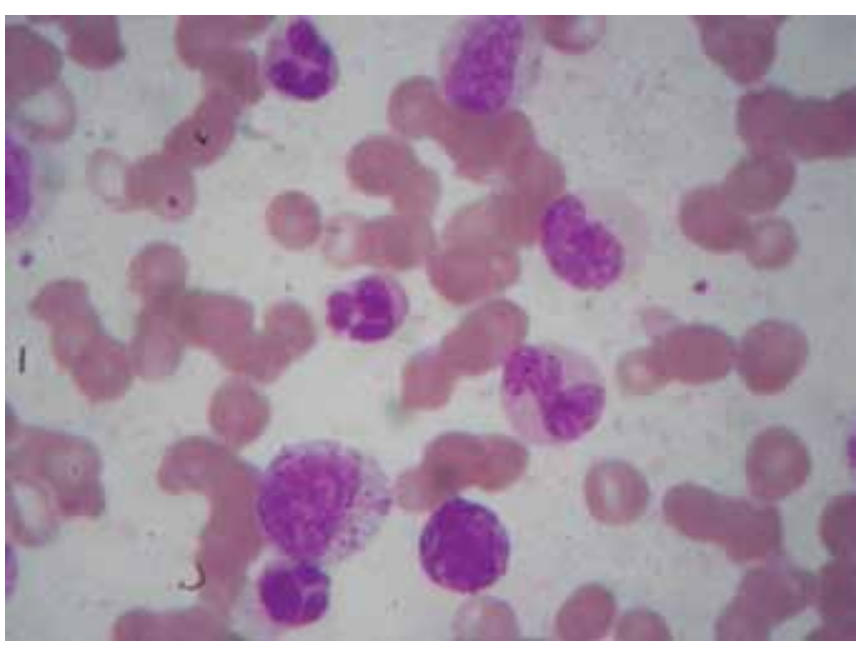

Fig. 1: Peripheral blood smear of CML in chronic phase. (Leishman, $\times 1000$ )

There is no evidence that the behavior of chronic myeloid leukemia is altered in pregnancy. ${ }^{8}$ However, there is a risk of leukostasis and placental insufficiency with consequent low birth weight, fetal prematurity and increased mortality if CML is left untreated during pregnancy.

The management of CML in pregnancy involves prevention of placental insufficiency and other complications of hyperleukocytosis by control of maternal leukocyte count, while avoiding harmful fetal exposure to cytotoxic drugs. There have been few reports of successful treatment of CML during pregnancy by therapeutic agents like hydroxyurea, busulfan, interferon $\alpha$ and imatinib. Leukapheresis is also being tried in few cases. However there has been no systemic investigation of the effect of these therapeutic options in pregnancy. ${ }^{9}$

As pregnancy does not alter the course of CML, the case can be managed by close observation without active intervention in the best interest of both the mother and fetus. However, if there is presence of symptoms, a rapidly increasing leukocyte count or emerging signs of a more advanced disease will mandate the need for immediate therapy.

\section{REFERENCES}

1. Brunning RD, Matutes E, Harris NL, et al. Chronic myelogenous leukemia. In: Jaffe ES, Harris NL, Stein H, Vardiman JW, editors. World Health Organization. Classification of tumours. Pathology

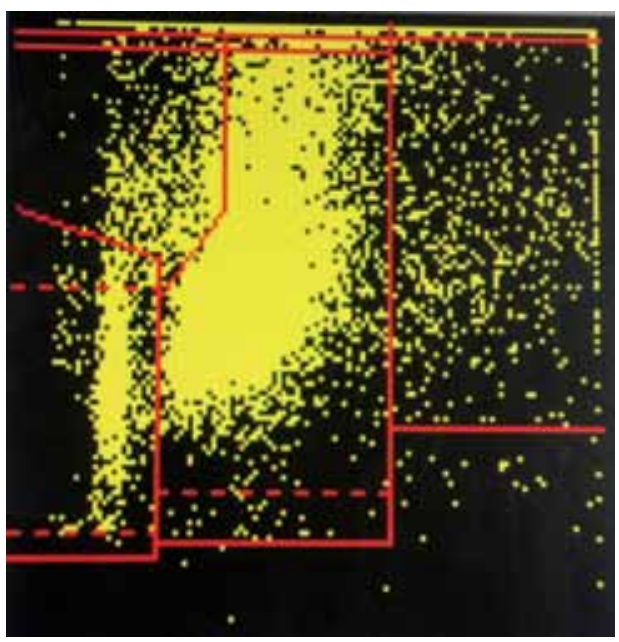

Fig. 2: Scatter diagram of CML

and genetics of tumours of hematopoietic and lymphoid tissues. 3rd ed. Lyon, France: IARC Press; 2001. p. 20-26.

2. Celiloglu M, Altunyurt S, Undar B. Hydroxyurea treatment for chronic myeloid leukemia during pregnancy. Acta Obstet Gynecol Scand 2000 Sep;79(9):803-804.

3. Lichtman MA, Liesveld JL. Acute myelogenous leukemia. In: Beulter E, Lichtman MA, Coller B, Kipps TJ, et al, editors. Williams Hematology. 6th ed. New York, NY: McGraw-Hill; 2001. p. 1074-1084.

4. Abramson S, Miller RG, Phillips RA. The identification in adult bone marrow of pluripotent and restricted stem cells of the myeloid and lymphoid systems. J Exp Med 1977 Jun 1;145(6):1567-1579.

5. Bennett JH. Case of hypertrophy of the spleen and liver in which death took place from suppuration of the blood. Edinb Med Surg J 1845;64:413-423.

6. Kantarjian HM, Smith TL, McCredie KB, Keating MJ, Walters RS, Talpaz M, Hester JP, Bligham G, Gehan E, Freireich EJ. Chronic myeloid leukemia: a multivariate analysis of the associations of patient characteristics and therapy with survival. Blood 1985 Dec;66(6):1326-1335.

7. Rowley JD. Letter: A new consistent chromosomal abnormality in chronic myeloid leukaemia identified by quinacrine fluorescence and Giemsa staining. Nature 1973;243:290-293.

8. Munkarah AR, Morris R. Malignant disease in pregnancy. In: James DK, Steer PJ, Weiner CP, Gonik B, editors. High risk pregnancy management options. 2nd ed. St. Louis, MO: WB Saunders; 1999. p. 954-955.

9. Firas AS, Demeckova E, Mistrik M. Leukemia in pregnancy. Bratisl Lek Listy 2008;109(8):364-366. 